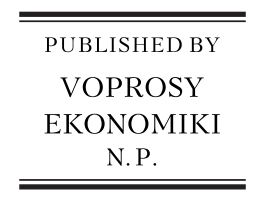

Russian Journal of Economics 6 (2020) 339-346 DOI 10.32609/j.ruje.6.61832

Publication date: 14 December 2020
Russian

Journal of Economics

www.rujec.org

\title{
Foreword
}

\section{Energy transition and game changers}

\author{
Leonid M. Grigoryev*
}

HSE University, Moscow, Russia

COVID-19 and the recession of 2020 will be remembered far longer than the crises of 2009 or 1974 - about like 1929. The latter are history - 2020, however, is a total game changer in many aspects of economic and social life, as well as in international relations. The energy transition has become the key theme in the world economy over recent years. But, all of a sudden, the mankind has had to confront the most dangerous pandemic to strike it in one hundred years. Against the background of climate-related droughts, floods and tornados, the pandemic has resulted in 50 million cases of infection and over a million fatalities in just six months. Lockdowns started in China in February, in Europe in March of 2020, and have been spiraling in the USA, Brazil, India and other developing countries. This is a transformation that has already affected all aspects of the process of sustainable development, as defined by the UN agreement in 2015 - Sustainable Development Goals (SDG), especially: Poverty (SDG 1), Healthcare (SDG 3) and Inequality (SDG10) (see Bobylev and Grigoryev, 2020). The problems of economic development and all the corresponding debates will now be categorized accordingly: before and after 2020. Energy and climate were game changers for the global economy before COVID-19 and the current recession, and they will stay that way after 2020 , but the details of this process are still to be studied and understood.

This issue of RuJE contains seven articles coinciding with this pivotal time: the previous trajectory after the Global Recession of 2008-2009 is constantly evolving and the deepest crisis since World War II is developing (IMF, 2020). So how to negotiate a new path is still the subject of debates and "scenarios." These articles analyze the outcome of recent trends in the field of global energy as well as the mechanisms of these dramatic changes in the business world, and public attitudes and government policies. At the moment we should consider the analysis and insights into current processes as intellectual instruments. Gazing into the crystal ball right now may be a question of analyzing causalities of the recession and its interactions with the pandemic, as well as the logic of interests and

\footnotetext{
* E-mail address: lgrigor1@yandex.ru
} 


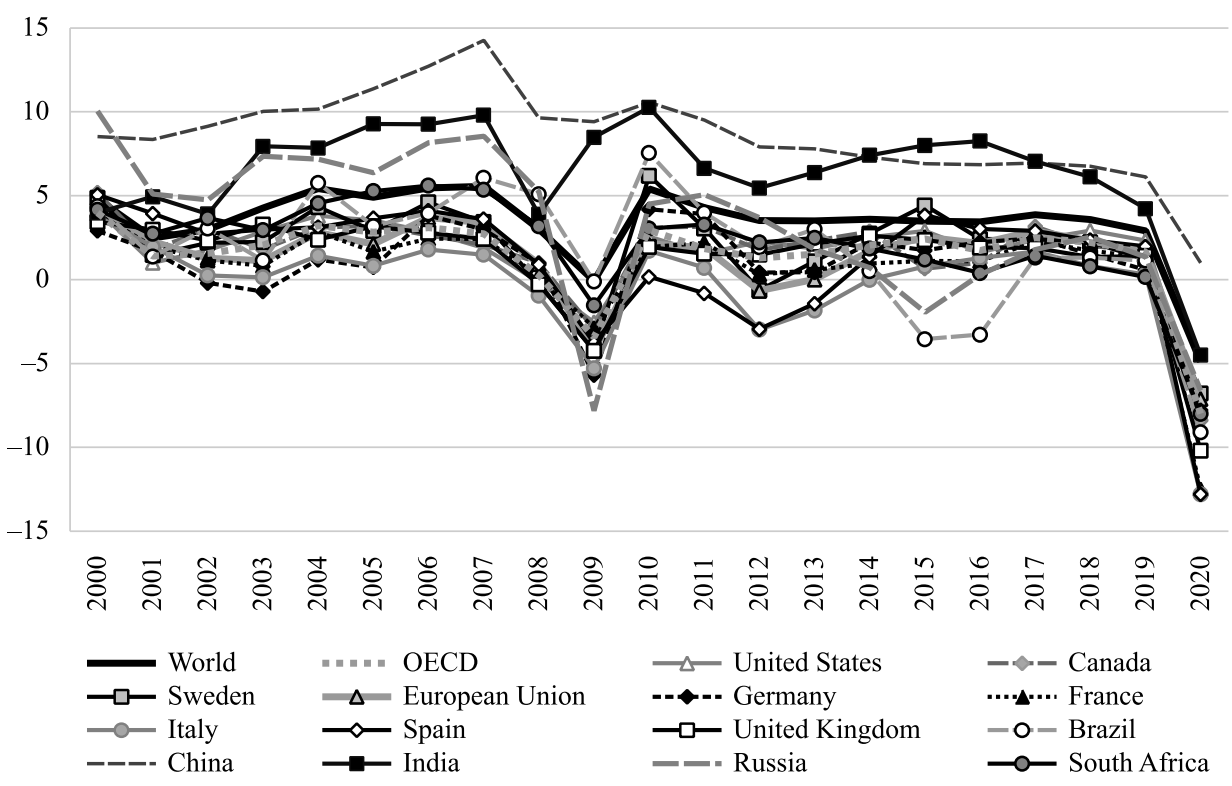

Fig. 1. GDP growth rates of selected countries and country groups, 2000-2020 (\%).

Source: IMF. World economic outlook database; IMF, 2020.

intentions of all parties (and actors) involved in the decision-making process. This is certainly an "interesting time" — as the oriental saying would have it.

We know enough about the current recession and its macroeconomic framework to be concerned about its impact on global development: it has inflicted a 4,4\% decline in global GDP (Fig. 1) and an 8\% decline in trade and minus 10 million barrels per day (mbd) of oil consumption. We naturally also expect a decline of some percentage points (6-7\%) in greenhouse gases (GHG) emission.

We also understand that central banks (including FRS and ECB) have added roughly 5 trillion dollars as emergency liquidity in 2020. In this period of reduced investment, the additional liquidity with low interest rates has supported stock prices and the price boom in real estate markets. That is a background for investment decisions with low interest rates and uncertain demand - a picture rather reminiscent of the credit crunch a few years ago. At this time of severe crises, we would expect the overlapping impact of three types of corrections in the investment process: lack of financing for certain types of projects in spite of cheap money conditions; the revision of timing and tactical delays of realization (and minor "alterations") due to uncertainties and risks; and the revision and changes of types and parameters of projects due to strategic changes in economic growth and technological, geographical and industrial development.

The first article of this issue belongs to prominent energy economists Alexey Makarov, Tatyana Mitrova, and Vyatcheslav Kulagin. It is devoted to "Long-term development of the global energy sector under the influence of energy policies and technological progress." Essentially, this article has two major justifications for occupying its position. First, this is an insight into forecast-making by one of a few major models in the world of energy-forecasting that belongs in the same group as EIA of the US, IEA and a few models from corporations. It is important to state that this group of forecasters base their scenarios for 
energy policies and technological progress on rational economic logic. Secondly, the forecasts are based on a complex model with rational assumptions and connection with the demand and supply on energy markets (Makarov et al., 2019). That approach shows how the energy world is being driven by market forces, technological progress and energy (economic, climate) policies, but not by political non-economic considerations.

Forecasting in a period of major change, against the background of COVID-19 and the recession, is especially difficult because of uncertainty surrounding all economic agents, business or government, as well as the timing and character of decision-making in the new environment. The authors demonstrate how the pandemic and the recession have changed oil and gas markets. The most practically important input arises from the prices' curve for both markets under conservative and transition scenarios. Predictions (derivations) are particularly important for practical purposes. An agreement on production limitations among producers may keep prices for oil above $\$ 50$ per bbl; gas prices could remain relatively stable although regional markets could still maintain some differences. For coal, on the other hand, there could be a substantial reduction of prices in the event of transitional policies. To some extent the authors show how climate policies are winning over time, while reducing the cost of fossil fuels for consumers.

The second article covers a vast field: "Renewables and the future of geopolitics: Revisiting main concepts of international relations through the lens of renewables." The authors - Emre Hatipoglu, Saleh Al Muhanna, and Brian Efird - have built their innovative analysis on a considerable number of relevant publications, so underlying the importance of the subject. Few major topics have been given such an innovative and in-depth approach. It starts with the observation that solar and wind power installations (including grids) tend to require close to 100 times more area than traditional thermal power; they are vulnerable to the risk of civil strife and cyber-attack. The issues of transit trade, and different legal and commercial aspects of the intensive trade of renewables are considered to be special cases of economic interdependence, and geopolitical events can also affect infrastructure decisions for renewables.

Actually, renewable energy sources (RES) do not eliminate the problem of security of supplies and transfers (in interstate relations) but modify it - and the authors reasonably call it a new form of interdependence. That approach may also involve relations in the case of national and sub-national (international) grids. They warn us: "Future technologies create a catch-22 situation as digitalization and inter-connectivity will likely lead to an upgrade in equipment that is more secure, yet inter-connectivity may also lead to increased inter-dependence and thus pose a higher cyber-risk."

The wide use of RES in all global scenarios of energy transition probably underestimates a further problem, which is stressed in the article: the competition between countries and industries (e.g., energy vs. defense) for rare earth metals and minerals such as lithium, cobalt, graphite and vanadium, critical to manufacturing and maintaining renewable energy products and installations. This is a sobering addition to the debates on the coming total replacement of fossil fuels by RES: "Renewable energy creates new forms of interdependency between states that may either foster cordial or conflictual relations." Nothing is devoid of cost, and international relations in the energy world will continue to be affected now and in the future. 
The third article is focused on European transition to the future: "Priorities and challenges of the EU energy transition: From the European Green Package to the new Green Deal" by Manfred Hafner and Pier Paolo Raimondi. The authors give a full-fledged account and analyze the growing ambition of the European Union to lead the global transition to a climate-neutral world. The steps, taken by EU authorities towards this goal, reflect the determination of member states as well as widespread political and popular support.

In our opinion, the actions of the EU leadership send the message that it is not easy to solve the Climate change prevention task in line with the Paris agreement and in the framework of the UN SDG process. The authors show how the EU has been continuously raising the stakes and targets in its climate policy since the Green Package agreement, proposed in 2007 and reached in 2009. They recognize the role of delocalization of industrial production and activities out of the EU climate jurisdiction in the reduction of GHG emissions regionally, but not globally. The Great Recession of 2009 and economic recovery (before the events of 2020) helped reduce GHG emission and increased the rate of RES in 2018 up to $18 \%$ of final energy consumption.

Meanwhile, the target of decarbonizing the EU by 2050 is by no means assured. To some extent the major stumbling block is coal production and consumption in six countries of the EU. That section of the article is very important to the whole EU energy story because it goes far beyond green scenarios and explores real socio-political limitations (and costs) on decision making. The planning of financial resources concerning the coal regions' restructuring in Germany and Poland gives us some indication of the overall costs of phasing out coal globally. And then there is the European Green Deal of 2019 to consider. The authors have described the latter and the connected investment and financing plans in details available at the start of the pandemic and the recession of 2020. We should say that this downturn is certainly reducing the emission of GHG but also greatly reducing the financial resources of the EU member states who have to divert available funds towards containing the pandemic and measures to counteract the crisis, as well as poor strata and small and medium-sized enterprises (SMEs). The authors also touch upon European-Russian energy relations, looking for a positive role of Russia in the decarburization of EU. We also believe it would be reasonable to underline that the Green Deal does not question the capability and necessity of the Russian economy to keep supplying declining volumes of energy to the EU for the next three decades, sufficiently investing in energy and assuring the socioeconomic stability for EU decarbonization. The recession of 2020 will change a lot in the resource base and instruments of Green Deal but not overturn ambitious targets given the success of post-pandemic and post-recession recoveries. How the EU drive may affect the global energy transition is not clear in 2020.

The fourth article by Prof. Jonathan Stern "The role of gases in the European energy transition" suggests an interesting approach to the role of gases in the global economy, especially in the EU. He bases his evaluation of the next three decades on the forecast for global demand of gases, which will reach its peak by 2030 in North America, Eurasia and China, and then subsequently contract by 2050. The peak for Latin America, India and Africa is envisioned to occur later-by 2040. Actually the logic of European objectives makes local market dependent on decarbonization per se. The developing world in Asia 
and Africa may be more interested in improving the ecological situation in big cities en route to phasing out coal consumption. We would reiterate here, that, in our opinion, the social-economic costs of restructuring coal mining regions may be very high economically and politically — as has been the case in Poland and Germany to date. As a result, world demand may be diverging down different paths. In Asia and other regions, the demand for liquefied natural gas (LNG) may be higher given the relatively low prices. Later on, LNG producers will need "revolutionary" technologies of decarbonization as well, while the $\mathrm{CO}_{2}$ would be stored close to where it is produced in depleted fields. The author states, quite correctly, that the steps taken by "the gas community which focused on coal to gas switching and backing up renewables with gas while logical, failed to convince governments, NGOs, and media commentators that it could achieve longer term decarbonisation targets."

That situation may result in a different type of decision-making in the gas industry. LNG can stay as a de facto bridge fuel outside the EU longer than in the rest of the world. Accordingly, it may lead gas exporters to the EU to turn to different technological approaches - notably biomethan and hydrogen. Pipeline systems may be also used for these fuels. Currently, the costs of producing renewable hydrogen are too high for business projects, and the forecast for affordable prices indicates 2050 as the year of comparable costs for biomethan and hydrogen. Meanwhile, it requires more certification, border taxes and other measures with pressure on the pipelines suppliers to the EU. The author suggests that exporters look into options of decarbonization of gases and use the existing pipeline systems for their transport. On our part, we feel obliged to mention the uncertainty regarding the cost effectiveness of decarbonization of gases, affected simultaneously by low prices for gas and the high investment cost of the project, and with the prospects of declining demand and tax deductions. But that would require a very complex model of a few simultaneous equations from quite different sciences.

The fifth article was delivered by Kirsten Westphal on "German-Russian gas relations in face of the energy transition." The author treats the field of discussion in a few dimensions: as a part of historically tested alliance between Russia and Germany developed and framed over time; as the 'energy diplomacy' case; and as structural changes in the relations (power shifts) between an exporting country and an importing one. But, of course, this is against the background of security of supplies and decarbonization issues in European/Germany politics.

The author gives a wide display of Germany-USSR/Russia relations with a solid statement: "To summarize, the first thirty years were shaped by corresponding political and economic interest, growing and stable gas demand, balanced interdependence and technology cooperation beneficial to both sides." Later, following the EU's enlargement and the crisis of 2009, accompanied by internal EU debates on energy policy, bilateral relations have become dependent - as we would describe them - on external factors.

German policy has become progressively more climate concern driven, while as the author underlines: "Moscow's position has always been ambivalent visà-vis the climate agreements" (on this matter see Grigoryev et al., 2013). From the Russian retrospective view, it is hard to believe that in spite of the fact that all and every pretext had damaging effects on bilateral relations, especially on gas relations, the latter are still intact to a considerable extent. With German of- 
ficial intentions to "go green" by 2050 by phasing out nuclear, domestic coal and all fossil fuels, the country needs reliable gas supplies to cope with a period of energy transition. And as Professor Stern stated in the previous article, pipeline gas may have some technological advantages in the long run against the LNG.

The important feature of the article is the insight into interaction between rational energy developments, political disturbances and decarbonization policies: "When the gas glut was in full swing, Nord Stream 1's first pipeline was completed in June 2011... The new situation of the Third Energy Package in place resulted in quarrels around the onshore pipeline connections. Moreover, volumes sent through Ukraine decreased after the construction of Nord Stream 1 (see Grigoriev, 2010), whereas the transit volumes through Yamal were unaffected, making it a beacon for Nord Stream 2." And arriving at conclusions at the time of writing (November 2020) is made harder by an array of uncertainties: Nord Stream 2 is currently the focus of all political and rational economic considerations; then there is COVID-19 and the effects of recession and the impact of the American elections. The author concludes thus with regard to the current problems: "Russian gas supplies are seen as being antagonist to a (1) carbon-neutral energy system and (2) as divisive inside the EU with Nord Stream 2 as the linchpin. Even at the minimal contractual quantities ("take or pay" volumes), they guarantee nearly 40 bcm per annum of Russian gas exports to Germany beyond 2030."

The sixth article is "Fossil fuels markets in the 'energy transition' era" by Vyatcheslav Kulagin, Dmitry Grushevenko and Nikita Kapustin. The approach in this case is based on market studies for each fossil fuel in the presumption of rational development: economic growth, technology, efficiency, competition. The motto is: "For each of the conventional fuels the key drivers of the energy transition create their own challenges." The article provides an accurate step-bystep evaluation of such interesting and important issues as traditional cars and electric cars with subsidies also factored in. The presented picture mostly reflects the pre COVID-19 situations and interconnections which provide the basis for looking for another round of changes from it.

Generally, the article is "technology friendly" while avoiding overoptimistic expectations on efficiency and decarbonization. One may call this approach on energy transition as "optimism through a rational lens." The important feature of the approach is the independent forecasting for long-term economic development. It is not dependent on any "pre-set" agenda, political results, or necessity to fit into other popular frames. The article gives results generally in line with major global outlooks (IEA, EIA, etc.), but differs from normative optimism of some EU targeted scenarios. At the same time, the article is rather optimistic on the critical issue of phasing out coal consumption in China, as the peak passed in 2013-2014.

The authors have interesting points for future global (not particularly European) development of the gas sector: "For the gas industry, 'energy transition' presents a window of opportunity. Firstly, due to the rapid growth in demand for energy in the power generation sector, where gas is the most attractive of the fossil alternatives. Secondly, because gas has good potential as a backup fuel for RES, at least until other effective technical and economic solutions for load balancing appear." Some prospects for the oil sector may need revision with underlined risks from electric cars in the future. COVID-19 and the recession of 2020 are changing rationalities for transportation, urbanism and governmental policies, which may 
affect the composition of the global energy balances. But except for the period of deep recession the long-term consequences of lockdowns and infections' isolations are not yet clear.

Finally, the seventh article "Global energy trilemma" by Leonid Grigoryev and Dzhanneta Medzhidova, returns us to the depth of interaction between growth, poverty, inequality and energy and climate change prevention problems. The difficult year of 2020 has already added 150 million people in poverty according to the World Bank (2020). The authors argue that in the framework of SDG the Climate change and Energy transition goals have a certain priority over the Growth and Poverty ones. Essentially the authors are asking a rather simple and straightforward question: if the European Union succeeds in its fast decarbonization program by 2030-2050, but the Globe would have another billion poor people (including energy poverty), is it a satisfactory outcome of huge efforts of developed countries for the SDG process?

The authors actually call for "trilemma" approach: poverty \& inequalitygrowth - energy\&climate. To reach the UN Agenda 2030 will be very difficult in the years left after the recession of 2020. If we lose two or three years it will reduce the financial resources for development and energy transition, diverting them to poor and inevitable health care reforms. Investments are in decline globally in line with expectations during severe crises. Coordinated solutions are required to avoid aggravating global social problems.

Concerns for next decades:

- In spite of the definite progress of technologies and the slowdown in the GHG emission growth, the implementation of SDG before 2020 had been slow. No major action on the investment side had been taken - only individual countries (and the EU) initiatives.

- Poverty (including energy poverty) is far from being alleviated, and demographic factors probably play their dramatic role; expectations for 2040 are far from optimistic.

- Inequality is rigid - both social and inter-country; prospects for improvement are uncertain in the best case; the future accordingly breeds new risks (unrest, migration, etc.); yet no indicators on SDG 10 so far.

- COVID-19 brings the problem of poverty and inequality in health systems - another call for coordinated actions and changes in SDG 3.

- All the financial burden of the pandemic is a draw on financial resources of the developed countries and multinationals. The key focus of governments at the moment is helping the poor, limiting unemployment, protecting SMEs, etc. Financial stability and debt burden will become pressing issues in the near future.

- It means further reduction of resources for energy transition. Another concern is that ambitious plans lead to an escalation of targets at the time of scarcity. Low level of global cooperation may result in less efficient use of resources in the long run. Cost/effectiveness of policy instruments varies by countries for three reasons: different intensity of emission (say Sweden vs. India); different institutions and different level of development.

- Generally, the current situation requires a deep analysis of institutional settings and macroeconomics of the pandemic and the recession for long-term development, SDG process and energy transition. 


\section{References}

Bobylev, S., \& Grigoryev, L. (2020). In search of the contours of the post-COVID Sustainable Development Goals: The case of BRICS. BRICS Journal of Economics, 1(2), 4-24. https:// doi.org/10.38050/2712-7508-2020-7

Grigoriev, L. (2010). Happy end of pipeline conflicts? Baltic Rim Economies, 1, 13.

Grigoryev, L., Makarov, I., \& Salmina, A. (2013). Domestic debates on climate in Russia. In D. K. Vajpeyi (ed.). Climate change, sustainable development, and human security (pp. 249-280). Lanham, MD: Lexington Books.

IMF (2020). World economic outlook: A long and difficult ascent. Washington, DC: International Monetary Fund.

Makarov, A. A., Mitrova, T. A., \& Kulagin, V. A. (eds.) (2019). Global and Russian energy outlook. Moscow: ERI RAS \& Moscow School of Management SKOLKOVO. 